\title{
Photochemical Transformations of Chalcone-Vitamin E Hybrids
}

\author{
Jimmy Josué Ceballos-Cruz ${ }^{1}$, Jean-Jacques Hélesbeux², Guillaume Viault², Denis Séraphin ${ }^{2}$, \\ Gumersindo Mirón-Lopez ${ }^{3}$, Rubén M. Carballo ${ }^{4}$, Pascal Richomme ${ }^{2}$, Luis Manuel Peña-Rodríguez ${ }^{1 *}$ \\ ${ }^{1}$ Unidad de Biotecnología, Centro de Investigación Científica de Yucatán, Mérida, Yucatán, México. \\ ${ }^{2}$ Univ Angers, SONAS, SFR QUASAV, F-49000 Angers, France. \\ ${ }^{3}$ Laboratorio de Resonancia Magnética Nuclear, Facultad de Química, Universidad Autónoma de Yucatán, \\ Mérida, Yucatán, México. \\ ${ }^{4}$ Laboratorio de Química Farmacéutica, Facultad de Química, Universidad Autónoma de Yucatán, Mérida, \\ Yucatán, México.
}

*Corresponding author: Luis Manuel Peña-Rodríguez, email: $\underline{\text { lmanuel@cicy.mx }}$

Received September 14 ${ }^{\text {th }}, 2021$; Accepted December $6^{\text {th }}, 2021$.

DOI: http://dx.doi.org/10.29356/jmcs.v66i1.1670

\begin{abstract}
Chalcone-vitamin E hybrids 6'-O-tosyl-3,4,5-trimethoxy- $\delta$-tocopherol-chalcone (1), 3,4,5trimethoxy- $\delta$-tocopherol-chalcone (2), 6'-O-tosyl-3,4,5-trimethoxy- $\delta$-tocopherol-retrochalcone (3) and 3,4,5trimethoxy- $\delta$-tocopherol-retrochalcone (4) were synthesized as part of a search for new biological activities in these types of derivatives. We report herein on the photoisomerization products of hybrids $\mathbf{1 - 4}$, and the effects of the solvent and substitution patterns in producing secondary products such as flavanone 6, 3deoxyanthocyanidin $\mathbf{8}$, and hemiketal 10. Photochemically-induced changes are considered important since structural modifications and/or the presence of additional products can affect the biological activity of this type of semisynthetic hybrids.
\end{abstract}

Keywords: Photoisomerization; substituent effects; solvent effects; aggregation; deoxyanthocyanidin.

Resumen. Los híbridos de chalcona-vitamina E, 6'-O-tosil-3,4,5-trimetoxi- $\delta$-tocoferol-chalcona (1), 3,4,5trimetoxi- $\delta$-tocoferol-chalcona (2), 6'- $O$-tosil-3,4,5-trimetoxi- $\delta$-tocoferol-retrochalcona (3) y 3,4,5-trimetoxi$\delta$-tocoferol-retrochalcona (4), fueron sintetizados como parte de la búsqueda de nuevos perfiles de actividad biológica para este tipo de derivados. En este trabajo reportamos los productos de fotoisomerización de los híbridos 1-4, y los efectos del disolvente, así como de distintos patrones de sustitución en la generación de productos secundarios como la flavanona 6, la 3-deoxiantocianidina 8, y el hemicetal 10. Los cambios fotoinducidos son considerados de gran importancia debido a que la modificación en la estructura y/o la presencia de productos adicionales puede afectar la actividad biológica de este tipo de híbridos semisintéticos. Palabras clave: Fotoisomerización; efectos del sustituyente; efectos del disolvente; agregación; deoxiantocianidina.

\section{Introduction}

Vitamin E is a group of phytochemicals comprising two major classes, tocopherols and tocotrienols, which share a common chroman-6-ol ring bearing a geranylgeranyl side chain in tocotrienols, and a fully saturated polypropenyl side chain in tocopherols [1]. Both are naturally occurring metabolites found in fruits, 
vegetables, nuts and edible oils, with tocotrienols having a more restricted distribution [2-3]. All vitamin $\mathrm{E}$ isoforms are potent antioxidants and exhibit anti-inflammatory effects. Mechanistic studies have demonstrated that the anti-inflammatory activity in in vitro and in vivo assays occurs through inhibition of ciclooxygenase-2 and 5-lipoxygenase [4], and suppression of signaling pathways of inflammatory mediators NF-kb and JAKSTAT6 and JAK-STAT3 [5]. Currently, inflammatory-related diseases are recognized as a major cause of morbidity in humans; since the inflammatory process can contribute to the development of more severe health problems such as cancer [5], development of anti-inflammatory drugs is an important subject for medicinal chemistry.

Chalcones are a group of secondary metabolites found in fruits and vegetables, characterized by a propenone core linking two phenyl rings [6]. Because of their diverse biological activities, which include antimicrobial, anticancer, antitumor, antioxidant, antihyperglycemic and anti-inflammatory, the chalcone skeleton is considered a privileged scaffold with potential in medicinal chemistry [7]. Recently, prenylated chalcones, and specifically pyranochalcones, have been investigated for their pharmacological properties, particularly a potent anti-inflammatory activity [8]. In view of this, the combination of two well-known precursors known for their anti-inflammatory activity, i.e. a chalcone and vitamin E, to produce a new class of pyranochalcones, represents a useful strategy for the preparation of new hybrids with an improved antiinflammatory activity. To date, the only report dealing with the preparation of similar chalcone-vitamin $\mathrm{E}$ hybrids describes the applicability of a synthetic method, without evaluating their biological activity [9].

Recently, as part of a project dealing with the search for new biological activities in chalcone-vitamin E hybrids we observed a photoisomerization of the propenone moiety in the reaction products. Since spatial arrangement is of great importance in the interaction of drugs with biological targets, careful attention should be paid to changes in the torsion angles of the bonds in the propenone moiety of the chalcone core which can occur as a result of $E-Z$ photoisomerization [10]. Furthermore, the many potential uses for chalcones in technology [11] and medicine [12], makes the possibility of phototransformation a major concern. Recent studies on the photoirradiation of chalcones and anthocyanins have contributed to the understanding of the network of chemical reactions that can occur in different reaction media [13-14], revealing that equilibrium in aqueous medium can lead to new skeletons depending on $\mathrm{pH}$, light, and substitution patterns [13]. We wish to report herein on the conditions favoring the photoisomerization of the propenone moiety in chalcone-vitamin $\mathrm{E}$ hybrids as well as on the structure of a number of secondary products obtained under these conditions.

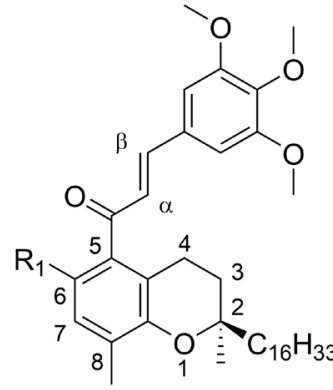

$1 \mathrm{R}_{1}=\mathrm{OTS}$

$2 \mathrm{R}_{1}=\mathrm{OH}$

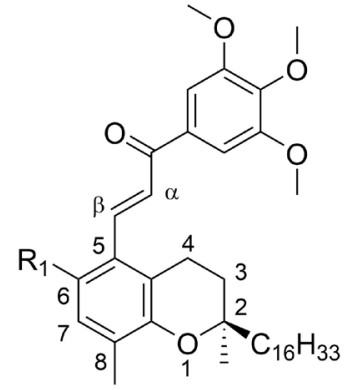

$3 \mathrm{R}_{1}=\mathrm{OTs}$

$4 \mathrm{R}_{1}=\mathrm{OH}$

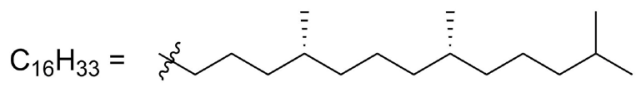

Fig.1. Structures of synthesized chalcone and retrochalcone-vitamin E hybrids: (E)-6'-O-tosyl-3,4,5trimethoxy- $\delta$-tocopherol-chalcone (1), (E)-3,4,5-trimethoxy- $\delta$-tocopherol-chalcone $(2),(E)$-6'- $O$-tosyl-3,4,5trimethoxy- $\delta$-tocopherol-retrochalcone (3) and $(E)$-3,4,5-trimethoxy- $\delta$-tocopherol-retrochalcone (4). 


\section{Experimental}

\section{NMR spectrometry}

${ }^{1} \mathrm{H}-\mathrm{NMR}$ and ${ }^{13} \mathrm{C}$ NMR spectra were recorded on a Bruker Avance or JEOL HY $400 \mathrm{MHz}$ NMR spectrometers, using the specified deuterated solvents and their corresponding residual solvent signals as internal reference. For monitoring, spectra were recorded at reported irradiation times using $4 \mathrm{mg} \mathrm{mL}^{-1}$ solutions for each analog.

\section{UV-visible spectroscopy}

UV-visible spectra (200-800 $\mathrm{nm}$ ) of 3 were recorded on an Agilent Cary $60 \mathrm{UV}$-Vis spectrophotometer using the specified solvent and spectra recorded at the specified irradiation times.

\section{Synthetic procedures}

$(E)-6$ ' $O$-tosyl-3,4,5-trimethoxy- $\delta$-tocopherol-chalcone $(1)$ and $(E)$-6' $O$-tosyl-3,4,5-trimethoxy$\delta$-tocopherol-retrochalcone (3)

In a $50 \mathrm{~mL}$ round bottom flask, 5 -acetyl-6- $O$-tosyl- $\delta$-tocopherol or 5 -formyl-6- $O$-tosyl- $\delta$-tocopherol $(0.36 \mathrm{mmol})$ was dissolved with ethanol $(10 \mathrm{~mL})$. A solution of 3,4,5-trimethoxybenzaldehyde or 3',4',5'trimethoxyacetophenone $(0.37 \mathrm{mmol}, 1$ equiv.) in ethanol $(5 \mathrm{~mL})$, and lithium hydroxide $(1.40 \mathrm{mmol}, 3.9$ equiv.) was added, and the reaction mixture was allowed to stir at room temperature $\left(25^{\circ} \mathrm{C}\right)$, until TLC showed the presence of the chalcone as the major product (cerium ammonium molybdate was used as stain). The reaction was quenched by adding $1 \mathrm{M} \mathrm{HCl}(5 \mathrm{~mL})$ until a color change from orange to yellow was observed; water was then added $(10 \mathrm{~mL})$ and the aqueous mixture was extracted three times with methylene chloride (15 $\mathrm{mL}$ ). The combined organic fractions were dried over anhydrous sodium sulfate, filtered and the solvent removed under reduced pressure. The residue was purified by flash chromatography eluting with a mixture of n-hexane and ethyl acetate $9: 1 \mathrm{v} / \mathrm{v}$, to yield $\mathbf{1}$ or $\mathbf{3}$.

(E)-6'- $\boldsymbol{O}$-tosyl-3,4,5-trimethoxy- $\boldsymbol{\delta}$-tocopherol-chalcone (1). (48 \% yield) Pale yellow oil $R_{f}=0.34$ (hexane-ethylacetate 8:2); ${ }^{1} \mathrm{H}$ NMR (acetone- $\left.d_{6}, 400 \mathrm{MHz}\right) \delta 7.66(2 \mathrm{H}, \mathrm{d}, J=8.2 \mathrm{~Hz}), 7.32(2 \mathrm{H}, \mathrm{d}, J=8.2 \mathrm{~Hz})$, $7.12(1 \mathrm{H}, \mathrm{d}, J=16.1 \mathrm{~Hz}), 7.01(1 \mathrm{H}, \mathrm{s}), 6.96(2 \mathrm{H}, \mathrm{s}), 6.81(1 \mathrm{H}, \mathrm{d}, J=16.1 \mathrm{~Hz}), 3.88(6 \mathrm{H}, \mathrm{s}), 3.78(3 \mathrm{H}, \mathrm{s}), 2.57$ $(2 \mathrm{H}, \mathrm{dt}, J=7.8,4.0 \mathrm{~Hz}), 2.30(3 \mathrm{H}, \mathrm{s}), 2.18(3 \mathrm{H}, \mathrm{s}), 1.84-1.68(2 \mathrm{H}, \mathrm{m}), 1.63-1.56(2 \mathrm{H}, \mathrm{m}), 1.55-1.49(2 \mathrm{H}$, $\mathrm{m}), 1.49-1.29(10 \mathrm{H}, \mathrm{m}), 1.28(3 \mathrm{H}, \mathrm{s}), 1.27-1.21(2 \mathrm{H}, \mathrm{m}), 1.19-1.06(8 \mathrm{H}, \mathrm{m}), 0.87(6 \mathrm{H}, \mathrm{d}, J=6.7 \mathrm{~Hz}), 0.86$ $(3 \mathrm{H}, \mathrm{d}, J=6.7 \mathrm{~Hz}) ;{ }^{13} \mathrm{C}$ NMR (acetone- $\left.d_{6}, 100 \mathrm{MHz}\right) \delta 193.7,154.8(2 \mathrm{C}), 151.5,146.9,146.6,141.7,139.3$, 134.0, 132.4, 131.1, 130.9 (2C), 129.4, 129.2 (2C), 127.8, 122.8, 120.2, 107.1 (2C), 77.4, 60.8, 56.7 (2C), 40.7, 40.2 , 38.3 (2C), 38.1, 38.1, 33.6, 33.5, 31.1, 28.8, 25.6, 25.2, 24.5, 23.1, 23.0, 21.7, 21.6, 21.1, 20.2, 20.2, 16.6.

(E)-6'-O-tosyl-3,4,5-trimethoxy- $\boldsymbol{\delta}$-tocopherol-retrochalcone (3). (50\% yield) Pale yellow oil $R_{f}=0.37$ (hexane-ethylacetate 8:2); ${ }^{1} \mathrm{H}$ NMR $\left(\mathrm{CDCl}_{3}, 400 \mathrm{MHz}\right) \delta 7.63(2 \mathrm{H}, \mathrm{d}, J=8.5 \mathrm{~Hz}), 7.58(1 \mathrm{H}, \mathrm{d}, J=15.9 \mathrm{~Hz})$, $7.48(1 \mathrm{H}, \mathrm{d}, J=15.9 \mathrm{~Hz}), 7.33(2 \mathrm{H}, \mathrm{s}), 7.18(2 \mathrm{H}, \mathrm{d}, J=8.5 \mathrm{~Hz}), 6.84(1 \mathrm{H}, \mathrm{s}), 3.97(6 \mathrm{H}, \mathrm{s}), 3.95(3 \mathrm{H}, \mathrm{s}), 2.74$ $(2 \mathrm{H}, \mathrm{t}, J=6.7 \mathrm{~Hz}), 2.37(3 \mathrm{H}, \mathrm{s}), 2.13(3 \mathrm{H}, \mathrm{d}, J=0.7 \mathrm{~Hz}), 1.87-1.70(2 \mathrm{H}, \mathrm{m}), 1.54-1.48(2 \mathrm{H}, \mathrm{m}), 1.45-1.26$ $(9 \mathrm{H}, \mathrm{m}), 1.25(3 \mathrm{H}, \mathrm{s}), 1.23-1.00(10 \mathrm{H}, \mathrm{m}), 0.86(9 \mathrm{H}, \mathrm{d}, J=6.7 \mathrm{~Hz}), 0.84(3 \mathrm{H}, \mathrm{d}, J=6.7 \mathrm{~Hz}) ;{ }^{13} \mathrm{C} \mathrm{NMR}\left(\mathrm{CDCl}_{3}\right.$, $100 \mathrm{MHz}) \delta 189.0,153.4(2 \mathrm{C}), 151.0,145.5,142.6,140.4,136.6,133.5,133.1,129.7$ (2C), 129.4, 128.7 (2C), $127.7,125.8,122.8,121.5,106.3(2 \mathrm{C}), 76.0,61.1,56.5$ (2C), 40.0, 39.5, 37.6 (3C), 37.4, 32.9, 32.8, 30.8, 28.1, $24.9,24.6,24.0,22.8,22.7,21.8,21.2,21.1,19.9,19.8,16.5$.

\section{$(E)-3,4,5$-trimethoxy- $\delta$-tocopherol-chalcone $\quad(2) \quad$ and $(E)-3,4,5$-trimethoxy- $\delta$-tocopherol- retrochalcone (4)}

In a $50 \mathrm{~mL}$ round bottom flask, a suspension of 3,4,5-trimethoxy-6'- $O$-tosyl- $\delta$-tocopherol-chalcone (1) or 3,4,5-trimethoxy-6- $O$-tosyl- $\delta$-tocopherol-retrochalcone $(3)(0.17 \mathrm{mmol})$ in $\mathrm{MeOH}(10 \mathrm{~mL})$ was refluxed for 5 minutes until complete dissolution. A methanolic solution $(5 \mathrm{~mL})$ of $\mathrm{NaOH} 2 \mathrm{M}$ was added and reflux continued until complete consumption of the starting material was observed by TLC. The reaction was quenched with $1 \mathrm{M} \mathrm{HCl}$ aqueous solution $(15 \mathrm{~mL})$ until a color change from red to yellow was observed; the 
resulting mixture was diluted with water $(10 \mathrm{~mL})$ and extracted three times with methylene chloride $(20 \mathrm{~mL})$. The combined organic fractions were dried over anhydrous sodium sulfate, filtered and after removing the solvent under reduced pressure, the crude reaction product was purified by flash chromatography, eluting with a mixture of $n$-hexane and ethyl acetate $9: 1 \mathrm{v} / \mathrm{v}$, to produce 2 or 4 .

(E)-3,4,5-trimethoxy- $\boldsymbol{\delta}$-tocopherol-chalcone (2). (43\% yield) Orange oil $R_{f}=0.34$ (hexane-ethylacetate $8: 2) ;{ }^{1} \mathrm{H}$ NMR (acetone- $\left.d_{6}, 400 \mathrm{MHz}\right) \delta 8.65(1 \mathrm{H}, \mathrm{s}), 7.39(1 \mathrm{H}, \mathrm{d}, J=16.0 \mathrm{~Hz}), 7.11(1 \mathrm{H}, \mathrm{d}, J=16.0 \mathrm{~Hz}), 7.03$ $(2 \mathrm{H}, \mathrm{s}), 6.64(1 \mathrm{H}, \mathrm{s}), 3.88(6 \mathrm{H}, \mathrm{s}), 3.76(3 \mathrm{H}, \mathrm{s}), 2.70(2 \mathrm{H}, \mathrm{t}, J=6.8 \mathrm{~Hz}), 2.14(3 \mathrm{H}, \mathrm{s}), 1.81-1.67(2 \mathrm{H}, \mathrm{m}), 1.63$ $-1.56(2 \mathrm{H}, \mathrm{m}), 1.55-1.48(2 \mathrm{H}, \mathrm{m}), 1.47-1.28(10 \mathrm{H}, \mathrm{m}), 1.27(3 \mathrm{H}, \mathrm{s}), 1.20-1.03(7 \mathrm{H}, \mathrm{m}), 0.88(3 \mathrm{H}, \mathrm{d}, J=$ $6.7 \mathrm{~Hz}), 0.87(6 \mathrm{H}, \mathrm{d}, J=6.7 \mathrm{~Hz}), 0.86(3 \mathrm{H}, \mathrm{d}, J=6.7 \mathrm{~Hz}) ;{ }^{13} \mathrm{C}$ NMR (acetone- $\left.d_{6}, 100 \mathrm{MHz}\right) \delta 196.9,154.7$ (2C), 149.7, 146.2, 144.7, 141.4, 131.5, 130.8, 128.8, 124.9, 119.8, 117.5, 106.9 (2C), 76.1, 60.7, 56.6 (2C), $40.6,40.2,38.3,38.2,38.1,38.1,33.6,33.5,31.9,28.7,25.6,25.2,24.5,23.1,23.0,21.9,21.7,20.2,20.1,16.8$.

(E)-3,4,5-trimethoxy- $\boldsymbol{\delta}$-tocopherol-retrochalcone (4). (55\% yield) Yellow gum $R_{f}=0.20$ (hexaneethylacetate 8:2); ${ }^{1} \mathrm{H} \mathrm{NMR}\left(\mathrm{CDCl}_{3}, 400 \mathrm{MHz}\right) \delta 7.96(1 \mathrm{H}, \mathrm{d}, J=15.7 \mathrm{~Hz}), 7.79(1 \mathrm{H}, \mathrm{d}, J=15.7 \mathrm{~Hz}), 7.29(2 \mathrm{H}$, $\mathrm{d}, J=0.9 \mathrm{~Hz}), 6.57(1 \mathrm{H}, \mathrm{s}), 3.93(9 \mathrm{H}, \mathrm{s}), 2.85(2 \mathrm{H}, \mathrm{t}, J=6.8 \mathrm{~Hz}), 2.16(3 \mathrm{H}, \mathrm{s}), 1.81(2 \mathrm{H}, \mathrm{m}), 1.53-1.47(2 \mathrm{H}$, m), $1.43-1.27(9 \mathrm{H}, \mathrm{m}), 1.25(3 \mathrm{H}, \mathrm{s}), 1.20-1.00(10 \mathrm{H}, \mathrm{m}), 0.86(6 \mathrm{H}, \mathrm{d}, J=6.7 \mathrm{~Hz}), 0.85(3 \mathrm{H}, \mathrm{d}, J=6.1 \mathrm{~Hz})$, $0.83(3 \mathrm{H}, \mathrm{d}, J=6.5 \mathrm{~Hz}) ;{ }^{13} \mathrm{C} \mathrm{NMR}\left(\mathrm{CDCl}_{3}, 100 \mathrm{MHz}\right) \delta 190.7,153.2(2 \mathrm{C}), 149.1,146.2,142.4,139.1,134.0$, 130.7, 125.3, 121.4, 118.1, 116.8, 106.3 (2C), 75.0, 61.1, 56.4 (2C), 39.8, 39.5, 37.6 (3C), 37.4, 32.9, 32.8, $31.3,28.1,24.9,24.6,23.8,22.8,22.7,21.3,21.1,19.9,19.8,16.6$.

\section{Results and Discussion}

During the synthesis of the chalcone and retrochalcone-vitamin E hybrids 1-4 (Fig. 1), the ${ }^{1} \mathrm{H}-\mathrm{NMR}$ spectrum of the purified protected $E$ chalcone 1 showed, in addition to the vinylic proton signals at $\delta 6.81(\mathrm{~d}, J$ $=16.1 \mathrm{~Hz}, \beta)$ and $\delta 7.12(\mathrm{~d}, J=16.1 \mathrm{~Hz}, \beta)$, the presence of a new set of signals at $\delta 6.28(\mathrm{~d}, J=12.8 \mathrm{~Hz}, \beta)$ and $\delta 6.84(\mathrm{~d}, J=12.8 \mathrm{~Hz}, \beta)$, which appeared over time. This suggested the possibility of an isomerization of the propenone moiety to produce the corresponding $Z$ (s-cis) isomer 5 . The fact that these changes were observed only when solutions of 1 in deuterated chloroform or acetone- $\mathrm{d}_{6}$ were exposed to sunlight (Fig. 2), and the absence of this new set of signals when similar samples were kept in the dark, confirmed that the changes were due to a photoisomerization process and ruled out the possibility of impurities present in the solvent being responsible for the changes.

Since photoisomerization of the propenone moiety in chalcones has been previously reported [1012,13,15], the potential photoisomerization of the chalcone-vitamin E hybrids $\mathbf{1}$ and $\mathbf{2}$, together with that of the corresponding retrochalcone hybrids $\mathbf{3}$ and $\mathbf{4}$, was studied theoretically using computational chemistry methods. Energetic calculations on the change of the torsion angle of the carbon-carbon double bond in the propenone moiety showed that the two pairs of $E$ chalcone/retrochalcone hybdrids follow a path that goes from the excited triplet state $\left(\mathrm{T}_{1}\right)$, passing through a conical intersection to get to the singlet state $\left(\mathrm{S}_{0}\right)$, to yield the corresponding $Z$ isomer (Fig. 3). Since the calculated energy required to excite $E$ chalcones 1-4 from the singlet to the triplet state is between $2.31-2.71 \mathrm{eV}$, and the fact that this amount of energy can be readily supplied by a photon of visible light [16], the photoisomerization of these four hybrids is expected to occur based on theoretical calculations.

To demonstrate that this process was responsible for the observed changes, ${ }^{1} \mathrm{H}-\mathrm{NMR}$ data was obtained during a time-course study in which samples of each hybrid (1-4), dissolved in either deuterated chloroform or acetone- $\mathrm{d}_{6}$, were exposed to sunlight for different periods of time (Fig. 1S-8S). Samples of the protected chalcone 1 dissolved in deuterated chloroform or acetone- $d_{6}$ showed evidence of a light-induced $E-Z$ isomerization by the presence of two $\mathrm{AB}$ spin systems corresponding to the $\alpha$ and $\beta$ protons of the propenone moiety of each isomer (Fig. 4). The photoisomerization of 1 reached equilibrium after $5 \mathrm{~min}$, showing a slightly higher proportion for $Z$ isomer (5) formation in the sample prepared in acetone- $d_{6}$ (Fig. 9S). However, when a solution of the unprotected chalcone $\mathbf{2}$ in deuterated chloroform was exposed to sunlight, no photoisomerization 
appeared to take place as indicated by the ${ }^{1} \mathrm{H}-\mathrm{NMR}$ spectrum of the sample. Alternatively, sunlight exposure of an acetone- $d_{6}$ solution of $\mathbf{2}$ for one hour led to flavanone $\mathbf{6}$, identified by the absence of the signals for the vinylic protons in its ${ }^{1} \mathrm{H}-\mathrm{NMR}$ spectrum and the presence of the characteristic signals corresponding to $\mathrm{H}-2$ ( $\delta$ 5.39 , dd, $J=13.4,2.9 \mathrm{~Hz})$ and H-3 $(\delta 3.06$, dd, $J=16.4,13.3 \mathrm{~Hz} ; \delta 2.73$, dd, $J=16.4,2.9 \mathrm{~Hz})$ of the flavanone's C-ring [Fig. 3S(e)].

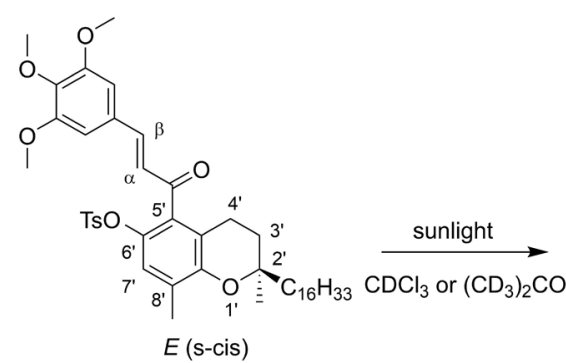

1

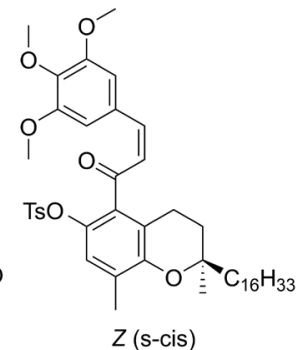

5

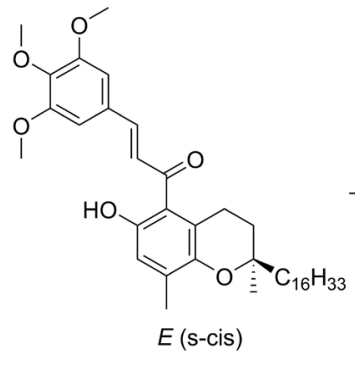

2

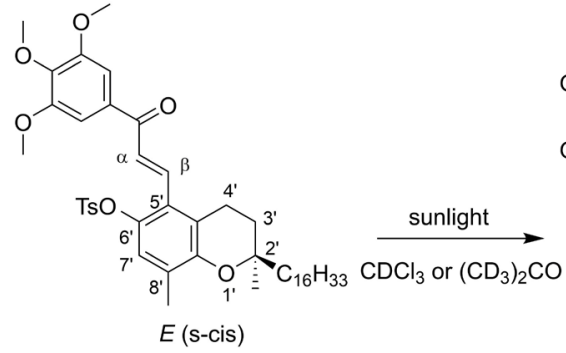

3

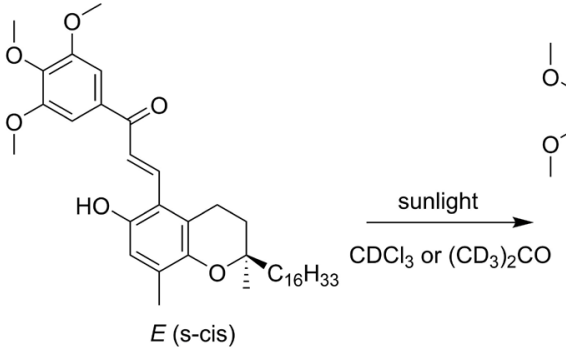

4

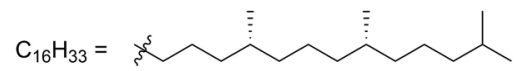

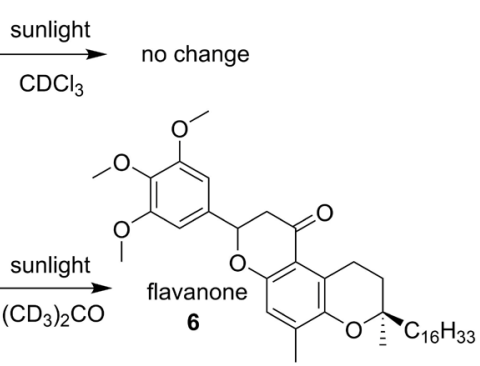

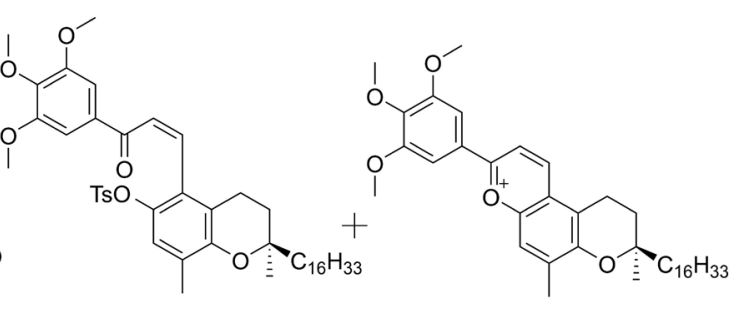

Z (s-cis)

7

3-deoxyanthocyanidin

8

Fig. 2. Chalcone and retrochalcone-vitamin E hybrids 1-4 and their photoisomerization products. (Z)-6'-Otosyl-3,4,5-trimethoxy- $\delta$-tocopherol-chalcone (5), 3,4,5-trimethoxy- $\delta$-tocopherol-flavanone (6), (Z)-6'-Otosyl-3,4,5-trimethoxy- $\delta$-tocopherol-retrochalcone (7), 3,4,5-trimethoxy- $\delta$-tocopherol-3-deoxyanthocyanidin (8), (Z)-3,4,5-trimethoxy- $\delta$-tocopherol-retrochalcone (9) and 3,4,5-trimethoxy- $\delta$-tocopherol-3deoxyanthocyanidin hemiketal (10). 
A)

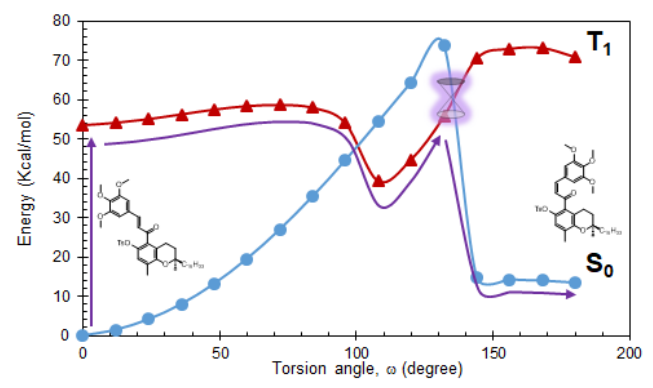

C)

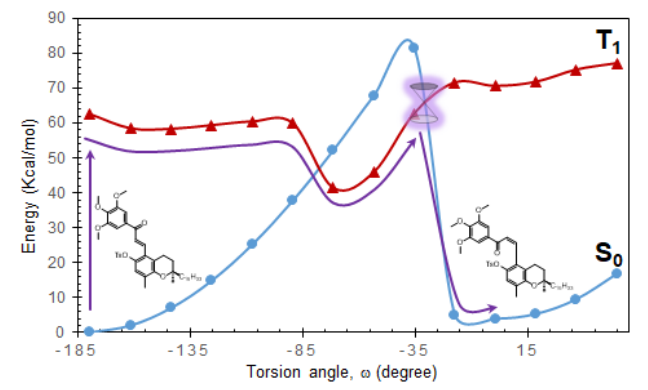

B)

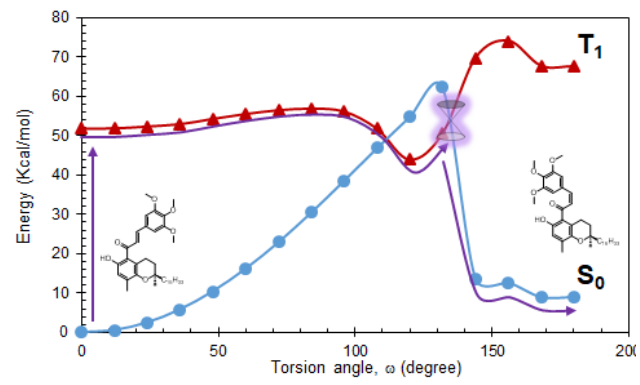

D)

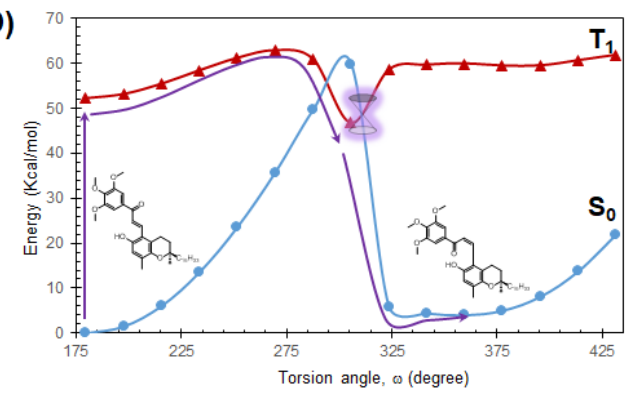

Fig. 3. Theoretical energy diagrams of the photoisomerization of the two pairs of $E$ chalcone/retrochalcone hybdrids. (A) tosyloxy-chalcone (1), (B) hydroxy-chalcone (2), (C) tosyloxy-retrochalcone (3), (D) hydroxyretrochalcone (4). Singlet state $\mathbf{0}$; triplet state $\boldsymbol{\Delta}$; suggested path for $E-Z$ isomerization $\mathbf{m}$.

Even though the photoreactivity of $E$-chalcones $\mathbf{1}$ and $\mathbf{2}$ coincides with that previously described for simpler chalcone analogs [17], the experimental results showed that this reaction does not take place in deuterated chloroform, and that the flavanone $\mathbf{6}$ is obtained in acetone- $d_{6}$ instead of the expected $Z$-chalcone. Similar cyclizations of simpler chalcone analogs of 2 leading to flavanone-type structures have been previously reported [17-18]; in these cases, formation of a six-membered tautomeric intermediate by means of an intramolecular hydrogen bond, between the carbonyl and the unprotected peri-hydroxyl group, reportedly favors the cyclization of the unprotected $E$-chalcone 2 rather than the expected $Z$-isomerization $[17,19]$. The inability of the $E$-chalcone $\mathbf{2}$ to form the flavanone $\mathbf{6}$ in deuterated chloroform under similar irradiation conditions, suggests that formation of the six-membered intermediate in this solvent is not favored.

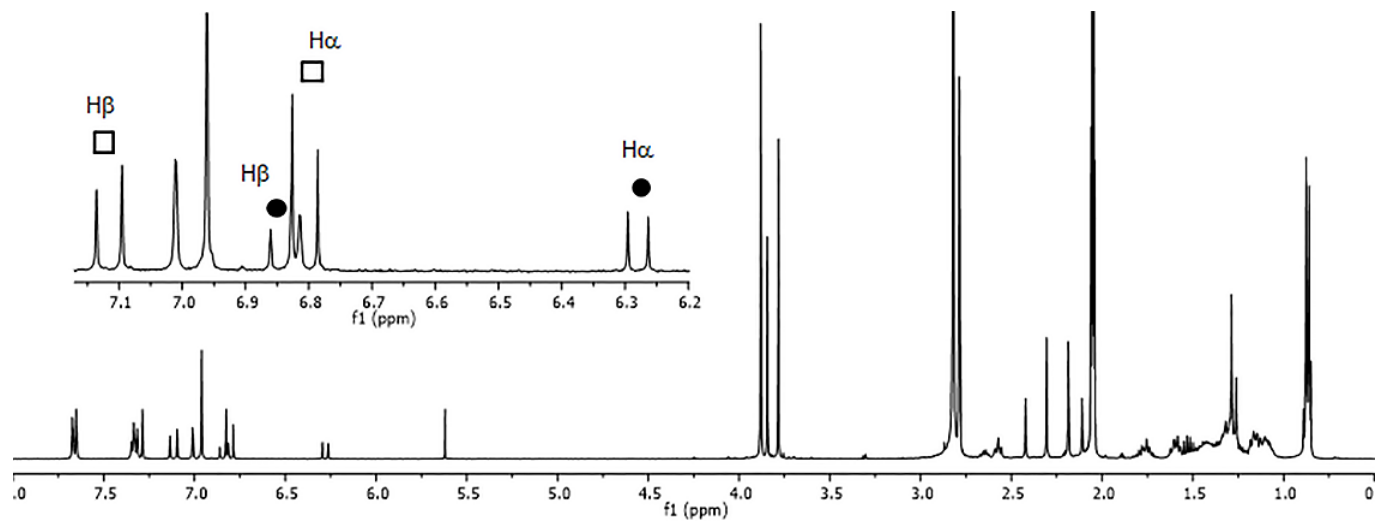

Fig. 4. ${ }^{1} \mathrm{H}-\mathrm{NMR}$ spectrum (400 MHz, acetone- $\left.d_{6}\right)$ of 1 after sunlight irradiation ( $t=20 \mathrm{~min}$ ): $E$ (s-trans) isomer $\mathbf{\square}, Z$ (s-cis) isomer 
Alternatively, sunlight exposure of both $E$-retrochalcone-hybrids $\mathbf{3}$ and $\mathbf{4}$ in deuterated chloroform and acetone- $d_{6}$ produced the expected photoisomerization products $\mathbf{7}$ and $\mathbf{9}$, respectively; additionally, cyclization products 3-deoxyanthocyanidin $\mathbf{8}$ and the hemiketal derivative $\mathbf{1 0}$ were also observed, with the latter identified on the basis of the characteristic H-3 and H-4 signals [20] at $\delta 5.86(\mathrm{~d}, J=9.8 \mathrm{~Hz})$ and $\delta 6.78(\mathrm{~d}, J=9.8 \mathrm{~Hz})$, respectively [Fig. $7 \mathrm{~S}(\mathbf{d})$ ]. The cyclization product 8 was identified on the basis of a new set of signals appearing at $\delta 9.29(\mathrm{~d}, J=9.1 \mathrm{~Hz})$ and $\delta 9.66(\mathrm{~d}, J=9.2 \mathrm{~Hz})$, which could be assigned to H-4 and H-3 of a flavylium system (Figures $6 \mathrm{~S}$ and $10 \mathrm{~S}$ ), respectively [21]. In addition to 7 and $\mathbf{8}$, the ${ }^{1} \mathrm{H}-\mathrm{NMR}$ of the crude photoisomerization reaction product from 3 showed weak signals at $\delta 4.96$ and $\delta 4.71$, suggesting the formation of a dimeric derivative bearing a cyclobutane core [22]. Even though similar dimers have been previously isolated from chalcone-rich sources, the limited number of examples, and the low yields in which they are obtained, indicate that formation of these type of products is not favored [23-25].

The formation of 3-deoxyanthocyanidin (8) could be detected by the presence of a band at $500 \mathrm{~nm}$, characteristic of flavylium-type skeletons [21,26], when using UV-vis spectroscopy to monitor the effect of sunlight irradiation on solutions of $\mathbf{3}$ in chloroform or acetone (Fig. 11S). These results, together with the development of a red pigmentation during sunlight irradiation of $\mathbf{3}$, confirmed the identification of $\mathbf{8}$. Although flavylium salts such as $\mathbf{8}$ are not expected to be stable in chloroform or acetone, its formation and stability could be explained on the basis of the amphiphilic properties of $\mathbf{8}$, since its positively charged "head" and its lipophilic "tail" could produce reverse micelle-type structures that encapsulate humidity in the medium (Fig. 12S) [2728].

The presence of different photoisomerization products during the irradiation of $\mathbf{3}$ indicates that their formation depends on the solvent used, with faster maxima on the production of both the $Z$ isomer 7 and the 3deoxyanthocyanidin $\mathbf{8}$ obtained in deuterated chloroform (Fig. 5). The favored formation of $\mathbf{8}$ in chloroform can be explained by the heterogeneity of the chloroform-water mixture which stabilizes micellar structures. Alternatively, the more hydrophilic acetone favors solubility and dispersion of the 3-deoxyanthocyanidin $\mathbf{8}$, which in turn reduces aggregation and, consequently, stability [29-30].
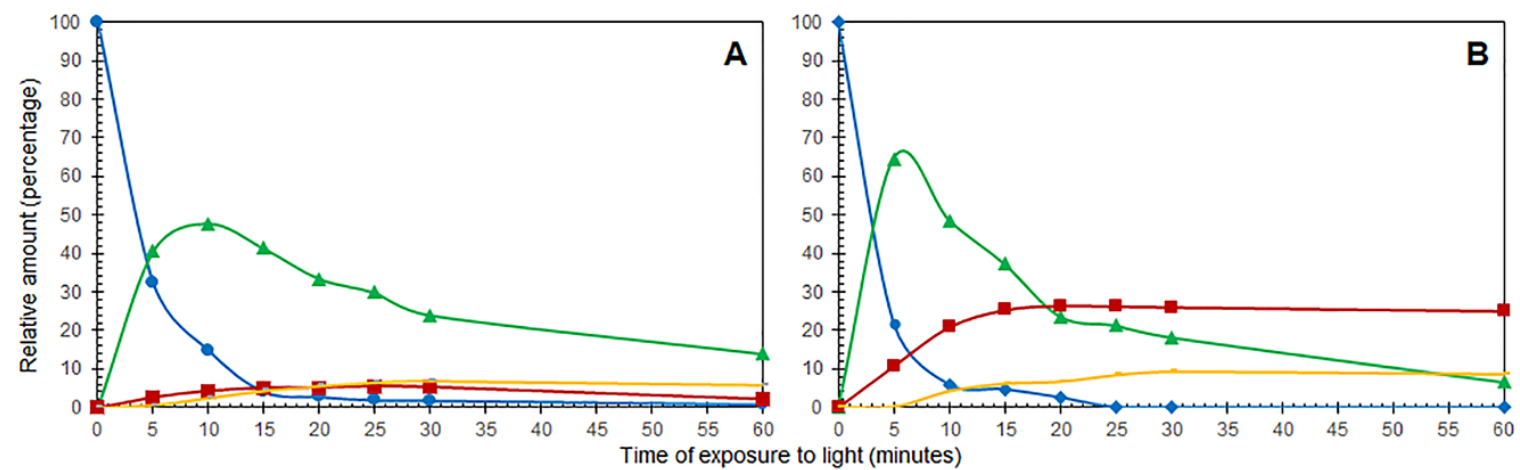

Fig. 5. Formation of photoisomerization products during light irradiation of $E$-retrochalcone 3 in acetone- $d_{6}$ (A); and in deuterated chloroform (B): E-retrochalcone $30, Z$-retrochalcone $7 \Delta, 3$-d eoxyanthocyanidin $8 \square$, cyclobutane core dimer $=$.

Finally, unlike the unprotected $E$-chalcone 2, the unprotected $E$-retrochalcone 4 did produce the expected photoisomerization product $\mathbf{9}$, together with the hemiketal derivative 10, when exposed to sunlight in both deuterated chloroform and acetone- $d_{6}$. In this case, the relative positions of the unprotected phenolic group and the conjugated carbonyl group in $\mathbf{4}$ prevented the cyclization to produce a flavanone-type product [26]. The formation of hemiketal $\mathbf{1 0}$ during the photoisomerization of $\mathbf{4}$, confirms that photoreactivity of chalcones can promote a complex equilibrium network to produce different derivatives [23,31].

It is interesting to mention that while formation of anthocyanins structurally similar to 8 has been reported to occur via an hemiketal intermediate during acid treatment of retrochalcones bearing an unprotected 
C-2 phenolic group [13], hemiketal $\mathbf{1 0}$ and 3-deoxyanthocyanidin $\mathbf{8}$ were not obtained as an intermediate and a product of the same reaction, but were obtained separately from the photoisomerization of the unprotected and protected $E$-retrochalcones $\mathbf{4}$ and 3, respectively. The fact that photoisomerization of the protected $E$ retrochalcone $\mathbf{3}$ produces $\mathbf{8}$, apparently without going through hemiketal intermediate $\mathbf{1 0}$, strongly suggests that the tosyloxy group in $\mathbf{3}$ plays a key role in the reaction, since tosyloxy groups are known to activate specific positions and to participate in different reactions. Even though examples of tosyloxy involvement in photochemical reactions are limited, the proposed photocyclization leading to the formation of $\mathbf{8}$ can only be explained through the participation of the tosyloxy group, as a leaving group during the final aromatization/oxidation step (Fig. 14S) [32-33].

Photo-induced changes in pharmaceuticals are a major concern during its development since any modification of the original structure and physico-chemical features can decrease, enhance or change a biological activity, and have a great impact in effectiveness and safety. However, the new chemical species obtained during the photoirradiation of chalcone-vitamin $\mathrm{E}$ hybrids 1-4 possess the potential to improve desirable properties such as the enhanced antiproliferative activity observed in chalcones isomerized from the $E$ to the $Z$ form [15], or the improved antiproliferative activity and cytotoxicity of chalcone dimers when compared to that of parent chalcones [25].

\section{Conclusion}

In summary, the results of this investigation confirm that chalcone-vitamin $\mathrm{E}$ hybrids are photosensitive pigments, and that their reactivity depends on both intrinsic and extrinsic factors such as substitution patterns and solvent of choice, respectively. Variations explored in solvents and substitution patterns, can influence the outcome of photo-induced processes, displaying formation of different chemical species. Even though chalcone transformation under light irradiation has been previously described, the results obtained in this investigation show that there exist new pathways in the photochemical reactivity network of chalcones to produce novel derivatives representing relevant scaffolds in the development of new pharmaceuticals.

\section{Acknowledgments}

The authors wish to thank Ramiro Felipe Quijano-Quiñones for theoretical calculations and Karlina García-Sosa and Mónica Nallely Arteaga-Rosas for technical assistance. JJC-C wishes to thank CONACYT for $\mathrm{PhD}$ scholarship No. 275151; financial support from SEP-CONACYT-ANUIES-ECOS-NORD (MexicoFrance) collaborative Project No. 276520 is also gratefully acknowledged.

\section{References}

1. Wong, W.-Y.; Ward, L. C.; Fong, C. W.; Yap, W. N.; Brown, L. Eur. J. Nutr. 2015, 56, 133-150. DOI: http://dx.doi.org/10.1007/s00394-015-1064-1

2. Khor, B.-H.; Tiong, H.-C.; Tan, S. C.; Wong, S. K.; Chin, K.-Y.; Karupaiah, T.; Ima-Nirwana, S.; Abdul Gafor, A. H. PLOS ONE 2021, 16, e0255205. DOI: https://doi.org/10.1371/journal.pone.0255205

3. Jiang, Q. Free Rad. Biol. Med. 2014, 72, 76-90. DOI: https://doi.org/10.1016/j.freeradbiomed.2014.03.035 
4. Harlan, L.; Mena, L. T.; Ramalingam, L.; Jayarathne, S.; Shen, C.-L.; Moustaid-Moussa, N. Nutrients. 2020, 12, 3356. DOI: https://doi.org/10.3390/nu12113356

5. Reiter, E.; Jiang, Q.; Christen, S. Mol. Aspects Med. 2007, 28, 668-691. DOI: http://dx.doi.org/10.1016/j.mam.2007.01.003

6. Shaik, A.; Bhandare, R. R.; Palleapati, K.; Nissankararao, S.; Kancharlapalli, V.; Shaik, S. Molecules 2020, 25, 1047. DOI: http://dx.doi.org/10.3390/molecules 25051047

7. Zhuang, C.; Zhang, W.; Sheng, C.; Zhang, W.; Xing, C.; Miao, Z. Chem. Rev. 2017, 117, 7762-7810. DOI: http://dx.doi.org/10.1021/acs.chemrev.7b00020

8. Damodar, K.; Kim, J.-K.; Jun, J.-G. Chin. Chem. Lett. 2016, 27, 698-702. DOI: http://dx.doi.org/10.1016/j.cclet.2016.01.043

9. Narender, T.; Papi Reddy, K. Tet. Lett. 2007, 48, 3177-3180. DOI: http://dx.doi.org/10.1016/j.tetlet.2007.03.054

10. Nicodem, D. E.; de M. G. Matos, J. J. Photochem. 1981, 15, 193-202. DOI: http://dx.doi.org/10.1016/0047-2670(81)87003-7

11. Sidharth, S. N.; Mashitah, M. Y.; Yuvaraj, A. R.; Hui, T. J.; Sarojini, B. K.; Hegde, G. Adv. Mater. Res. 2014, 1033-1034, 1149. DOI: http://dx.doi.org/10.4028/www.scientific.net/AMR.1033$\underline{1034.1149}$

12. Maldonado, T.; Ferraudi, G.; Lappin, A. G.; Godoy, F. Chem. PhotoChem. 2018, 2, 95-104. DOI: http://dx.doi.org/10.1002/cptc.201700129

13. Leydet, Y.; Batat, P.; Jonusauskas, G.; Denisov, S.; Lima, J. C.; Parola, A. J.; McClenaghan, N. D.; Pina, F. J. Phys. Chem. A 2013, 117, 4167-4173. DOI: http://dx.doi.org/10.1021/jp402761j

14. Pina, F.; Melo, M. J.; Laia, C. A.; Parola, A. J.; Lima, J. C. Chem. Soc. Rev. 2012, 41, 869-908. DOI: http://dx.doi.org/10.1039/C1CS15126F

15. Iwata, S.; Nishino, T.; Inoue, H.; Nagata, N.; Satomi, Y.; Nishino, H.; Shibata, S. Biol. Pharm. Bull. 1997, 20, 1266-1270. DOI: http://dx.doi.org/10.1248/bpb.20.1266

16. Yadav, L. D. S. Organic Spectroscopy, Springer, Dordrecht, 2005 (chapter 1), 4. DOI: http://dx.doi.org/10.1007/978-1-4020-2575-4

17. Norikane, Y.; Itoh, H.; Arai, T. J. Phys. Chem. A 2002, 106, 2766-2776. DOI: http://dx.doi.org/10.1021/jp0133081

18. Matsushima, R.; Kageyama, H. J. Chem. Soc., Perkin Trans. 2. 1985, 6, 743-748. DOI: http://dx.doi.org/10.1039/P29850000743

19. Norikane, Y.; Nakayama, N.; Tamaoki, N.; Arai, T.; Nagashima, U. J. Phys. Chem. A. 2003, 107, 8659-8664. DOI: http://dx.doi.org/10.1021/jp027824i

20. George, F.; Figueiredo, P.; Brouillard, R. Phytochemistry. 1999, 50, 1391-1394. DOI: http://dx.doi.org/10.1016/S0031-9422(98)00427-0

21. Devia, B.; Llabres, G.; Wouters, J.; Dupont, L.; Escribano-Bailon, M. T.; Pascual-Teresa, S. de; Angenot, L.; Tits, M. Phytochem. Anal. 2002, 13, 114-120. DOI: http://dx.doi.org/10.1002/pca.632

22.Zhang, X.-J.; Li, L.-Y.; Wang, S.-S.; Que, S.; Yang, W.-Z.; Zhang, F.-Y.; Gong, N.-B.; Cheng, W.; Liang, H.; Ye, M.; Jia, Y.-X.; Zhang, Q.-Y. Tetrahedron. 2013, 69, 11074-11079. DOI: http://dx.doi.org/10.1016/j.tet.2013.11.018

23. Pina, F.; Petrov, V.; Laia, C. A. T. Dyes Pigm. 2012, 92, 877-889. DOI: http://dx.doi.org/10.1016/j.dyepig.2011.03.033

24. Aljančić, I. S.; Vučković, I.; Jadranin, M.; Pešić, M.; Đorđević, I.; Podolski-Renić, A.; Stojković, S.; Menković, N.; Vajs, V. E.; Milosavljević, S. M. Phytochemistry. 2014, 98, 190-196. DOI: http://dx.doi.org/10.1016/j.phytochem.2013.11.025 
25. Menezes, J. C. J. M. D. S.; Diederich, M. F. Eur. J. Med. Chem. 2019, 182, 111637. DOI: http://dx.doi.org/10.1016/j.ejmech.2019.111637

26. Kalchevski, D. A.; Petrov, V.; Tadjer, A.; Nenov, A. Phys. Chem. Chem. Phys. 2018, 20, 8924-8934. DOI: http://dx.doi.org/10.1039/C8CP00602D

27. Correa, N. M.; Silber, J. J.; Riter, R. E.; Levinger, N. E. Chem. Rev. 2012, 112, 4569-4602. DOI: http://dx.doi.org/10.1021/cr200254q

28. Mulinacci, N.; Romani, A.; Pinelli, P.; Gallori, S.; Giaccherini, C.; Vincieri, F. F. Int. J. Pharm. 2001, 216, 23-31. DOI: http://dx.doi.org/10.1016/S0378-5173(00)00685-2

29. Ionescu, L. G.; De Fávere, V. T., in: Solution Behavior of Surfactants, Mittal, K. L.; Fendler, E. J., Eds., Springer, Boston, 1982, 407-416. DOI: http://dx.doi.org/10.1007/978-1-4613-3491-0 21

30. Sakhawat, S. S.; Ejaz-ur-Rehman, in: Interactions of Water in Ionic and Nonionic Hydrates, H. Kleeberg, Ed., Springer, Berlin, 1987, 251-255. DOI: http://dx.doi.org/10.1007/978-3-642-72701$\underline{6} 45$

31. Basílio, N.; Pina, F. Molecules 2016, 21, 1502. DOI: http://dx.doi.org/10.3390/molecules21111502

32. Neo, A. G.; López, C.; Romero, V.; Antelo, B.; Delamano, J.; Pérez, A.; Fernández, D.; Almeida, J. F.; Castedo, L.; Tojo, G. J. Org. Chem. 2010, 75, 6764-6770. DOI: http://dx.doi.org/10.1021/jo100742e

33. Charlton, J. L.; Lai, H. K.; Lypka, G. N. Can. J. Chem. 1980, 58, 458-462. DOI: http://dx.doi.org/10.1139/v80-073 